\title{
Studi Perencanaan Pembangunan Pembangkit Listrik Tenaga Panas Bumi Sebesar 120 MW di Blok Sarulla
}

\author{
B.H.M. Goldy Ompusunggu, Mahesa Ryan Pamuji, Gede Wibawa dan Kuswandi \\ Jurusan Teknik Kimia, Fakultas Teknologi Industri, Institut Teknologi Sepuluh Nopember (ITS) \\ Jl. Arief Rahman Hakim, Surabaya 60111 Indonesia \\ e-mail: gwibawa@chem-eng.its.ac.id
}

\begin{abstract}
Abstrak-Terus bertambahnya jumkah penduduk di Indonesia serta semakin majunya industri di Indonesia menyebabkan kebutuhan listrik Indonesia juga terus meningkat. Untuk memenuhi kebutuhan listrik yang terus meningkat ini pemanfaatan sumber energi selain fosil perlu dilakukan. Energi geothermal adalah salah satu energi alternatif yang ada di Indonesia. Sumber daya energi geothermal di Indonesia memiliki potensi yang sangat besar. Geothermal power plant ini didirikan di derah Blok Sarullam Sumatera Utara pada tahun 2020. Pabrik pembangkit listrik tenaga geothermal ini menggunakan proses integrated combined cycle, yang merupakan teknologi paling mutakhir dan baik diantara semua teknologi proses pembangkit listrik tenaga geothermal. Alasan pemilihan proses ini adalah kesesuaian dari karakteristik sumur geothermal dengan syarat dari pengaplikasian proses integrated combined cycle, yaitu memiliki entalpi yang tinggi. Proses ini menggabungkan teknologi proses binary cycle dan combined cycle sehingga transfer energinya maksimal dan memiliki efisiensi energi yang besar. Selain itu, pada proses integrated combined cycle $100 \%$ dari steam yang diambil dari sumur sumber panas bumi diinjeksikan kembali ke dalam sumber panas bumi sehingga umur sumur dan reservoir panas bumi dapat berproduksi lebih lama. Pada pabrik pembangkit listrik tenaga geothermal ini digunakan 2 jenis turbin, yaitu turbin uap untuk aliran fluida geothermal dan turbin gas untuk aliran working fluid iso-pentana. Proses geothermal power plant ini akan berlangsung secara kontinyu, yaitu 24 jam/hari dan 330 hari/tahun dengan perencanaan sebagai dengan kapasitas produksi $124 \mathrm{MW} /$ tahun dengan bahan Baku Feed dan IsoPentana sebanyak $1544832 \mathrm{~kg} / \mathrm{jam}$ dan $1634544 \mathrm{~kg} / \mathrm{jam}$. Berdasarkan analisis ekonomi dengan menggunakan metode pendekatan discounted cash flow yang terdiri dari perhitungan biaya prodiksi dan aliran kas/kinerja keuangan yang telah dilakukan, menghasilkan nilai Internal Rate of Return (IRR) 13,2 \%, Pay Back Period dengan 6,9 tahun dan BEP sebesar 30,9 \%.
\end{abstract}

Kata Kunci-Desain Pabrik, Geothermal, Sarulla.

\section{Pendahuluan}

B ertumbukkannya lempeng India-Asutralia dan lempeng Eurasia yang memanjang di sebelah barat Pulau Sumatera memungkinkan terbentuknya lokasilokasi sumber panas bumi yang berkaitan dengan gunung-gunung api muda. Hal ini berarti sistem panas bumi di Pulau Sumatera umumnya lebih dikontrol oleh sistem patahan regional regional yang terkait dengan sistem sesar Sumatera. Di Provinsi Sumatera Utara sendiri, sampai sekarang telah ditemukan 2 blok panas bumi yang terletak di Sarulla dan Sibayak. Pada tahun 1993-1998, Unocal, bekerjasama dengan PT. Pertamina, melakukan eksplorasi sumber panas bumi di Blok Sarulla. Eksplorasi dilakukan dengan cara membuat 13 sumur eksplorasi dan survey geologi, geokimia, serta geofisika pada sumur-sumur tersebut. Hasil dari eksplorasi ini adalah ditemukannya 3 sumber panas bumi baru di blok Sarulla, yaitu Sibualbuali, Silangkitang, dan Namora-I-Langit, dengan potensi energi sebesar 330 Mwe untuk 30 tahun.

Dengan potensi energi yang lebih besar serta karakteristik reservoir dan impurities yang lebih baik daripada Blok Sibayak, Blok Sarulla dipilih sebagai lokasi pembangunan pabrik pembangkit listrik tenaga panas bumi. Selain berdasar pada hasil pembandingan, faktor lain yang menjadi alasan pemilihan Blok Sarulla adalah 1. Ketersediaan Bahan Baku, dimana sumber panas bumi merupakan bahan baku dari pabrik pembangkit listrik tenaga geothermal. Blok Sarulla memiliki sumber panas bumi dengan rentang suhu 250$300{ }^{\circ} \mathrm{C}$ dan potensi energi sebesar 330 Mwe yang dapat digunakan selama 30 tahun, 2. Karakteristik Geothermal Fluids, dengan kondisi geothermal fluids di Sarulla tidak banyak mengandung $\mathrm{H}_{2} \mathrm{~S}$, hal ini menunjukkan bahwa resiko korosi pada fasilitas di pabrik pembangkit listrik tenaga panas bumi tidak besar dan juga steam yang digunakan aman untuk lingkungan, 3. Ketersediaan Lahan dengan luas wilayah kerja panas bumi di Blok Sarulla adalah 4,37458 $\mathrm{km}^{2}$, sedangkan luas dari Kabupaten Tapanuli Utara adalah $3.793,71 \mathrm{~km}^{2}$; dengan perbandingan 0,0012:1. Pemerintah sudah memberikan izin penggunaan lahan dengan SK Menteri Pertambangan dan Energi No.1521.K/034/M.PE/1990.

Kebutuhan listrik di Pulau Sumatera jauh lebih kecil dibandung dengan kebutuhan listrik di Jawa, dengan pangsa hanya sekitar $16 \%$ dari total kebutuhan listrik Indonesia pada tahun 2003 dan menjadi $18 \%$ pada tahun 2025. Mengingat Pulau Sumatera akan menjadi lumbung energi dan dapat dikatakan pemakaian listrik di pulau ini masih tergolong rendah menyebabkan peningkatan kebutuhan listrik di pulai ini diasumsikan lebih tinggi disbanding Jawa-Madura-Bali, yaitu sebesar $8.6 \%$ per tahun, dari 21.14 TWh pada tahun 2003 menjadi 128.91 TWh pada tahun 2025. Peningkatan pertumbuhan ebutuhan listrik $8.6 \%$ pada tahun tersebut juga dipacu oleh membaiknya perekonomian di Sumatera dan adanya program peningkatan rasio elektrifikasi di Sumatera. 


\section{URAIAN PROSES}

Proses pada Integrated Geothermal Power Plant terbagi menjadi dua bagian plant, yaitu dry steam power plant dan binary cycle power plant. Binary cycle power plant sendiri terbagi menjadi dua, yaitu proses dimana working fluid dipanaskan menggunakan kondensat dan working fluid dipanaskan menggunakan brine water. 118 MW SIL ; 240 MW NIL

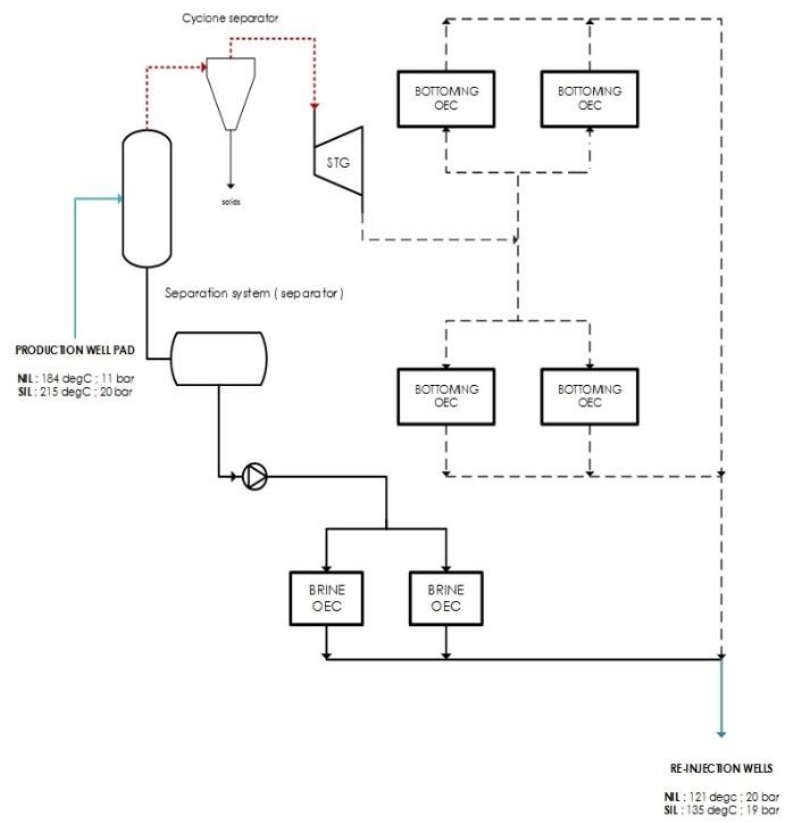

Gambar 1. Skema Integrated Combine Cycle Geothermal (ICCG) Plant

Uraian proses dari ICCG plant adalah sebagai berikut

\section{A. Pemisahan Uap Jenuh dari Sumber Sumur Produksi}

Campuran uap dan cairan dari sumur-sumur produksi dialirkan menggunakan sistem perpipaan menuju tangki pemisah yang berupa separation tank, dimana uap dan cairan akan dipisahkan. Separation tank dilengkapi dengan sistem pengaman berupa pressure safety valve dan rupture disc yang berfungsi sebagai pengaman apabila tekanan di dalam tangki melebihi batas resistensi tekanan tangki. Uap yang terpisah kemudian akan dialirkan menuju ke cyclone separator yang digunakan untuk memisahkan antara uap dengan padatan yang masih terbawa. Proses pemisahan uap dan padatan pada cyclone separator terjadi akibat adanya gaya sentrifugal, dimana fase solid yang memiliki densitas lebih tinggi akan menabrak dinding separator dan mengalir ke bawah. Sedangkan uap air akan mengalir keluar dari atas separator.

\section{B. Produksi Listrik Pada Direct Steam Power Plant}

Uap keluaran dari cyclone separator akan digunakan untuk memutar turbin. Dimana turbin akan terhubung langsung dengan generator AC yang berfungsi untuk mengubah energi gerak menjadi energi listrik. Pada proses lain, uap panas keluaran dari cyclone separator akan didinginkan dengan menggunakan cooler, namun pada proses di pabrik ini uap panas tidak didinginkan karena langsung digunakan untuk menggerakkan turbin.

\section{Proses Pemompaan dan Pemanasan Pada Bottoming ORC}

Pada Bottoming ORC digunakan working fluids yang memiliki titik didih lebih rendah sebagai penggerak turbin kedua. Dimana working fluids yang digunakan pada sistem ini adalah isopentane. Uap panas yang berasal dari turbin direct steam dialirkan melalui heat exchanger untuk menguapkan working fluids. Sebelum dialirkan ke heat exchanger, working fluids dipompa untuk menaikkan tekanan agar memiliki tekanan yang cukup untuk memutar turbin kedua. Ketika working fluids dan uap panas bertemu di heat exchanger pertukaran panas terjadi dan mengubah fase working fluids dari cair menjadi vapor. Working fluids yang telah berfase vapor kemudian dialirkan menuju turbin kedua untuk membangkit tenaga listrik.

\section{Proses Produksi Listrik Pada Bottoming ORC}

Working fluids dalam fase vapor digunakan untuk menggerakkan turbin kedua yang langsung berhubungan dengan generator listrik AC. Jumlah turbin pada sistem Bottoming ORC adalah dua. Working fluids vapor kemudian dialirkan menuju ke air cooled condensor untuk didinginkan sebelum dialirkan kembali ke pompa. Sistem bottoming ORC berupa closed loop, dimana working fludis tidak berkontak langsung dengan udara luar, proses closed loop berlangsung terusmenerus, Hal ini meyebabkan tidak dibutuhkannya penambahan working fluids terus-menerus, melainkan penambahan hanya dilakukan untuk make up dari proses.

\section{E. Proses Pemanasan dan Penguapan Working Fluids Pada Brine ORC}

Fluida panas yang berasal dari sepration tank disebut sebagai brine. Brine kemudian dialirkan ke dalam suatu sistem penukar panas berupa vaporizer dan preheater, rangkaian panas yang terdiri dari dua tahap. Brine yang baru keluar dari seprator memiliki suhu yang tinggi kemudian dilewatkan ke vaporizer, yang merupakan tahap kedua dari pemanasan, untuk menguapkan working fluids. Brine yang keluar dari vaporizer memiliki suhu yang sudah lebih rendah, tetapi masih dapat digunakan untuk memanaskan working fluid pada tahap pertama pemanasan, yaitu pada preheater. Working fluids dilewatkan ke preheater terlebih dahulu, kemudian dilewatkan ke vaporizer untuk tahap kedua pemanasan. Working fluids yang keluar dari vaporizer sudah berubah fase menjadi vapor. Working fluids yang sudah berfase vapor kemudian dialirkan ke turbin.

\section{F. Proses Produksi Listrik Pada Brine ORC}

Working fluids dalam fase vapor digunakan untuk menggerakkan turbin kedua yang langsung berhubungan dengan generator listrik AC. Jumlah turbin pada sistem Bottoming ORC adalah dua. Working fluids kemudian dialirkan menuju ke recuperator, kemudian dialirkan ke air cooled condensor. Working fluids yang sudah didinginkan kembali menggunakan air cooled condensor berubah fase menjadi cair kembali. Kemudian dipompa menuju ke recuperator untuk dipanaskan menggunakan working fluids panas yang berasal dari turbin. Pemompaan bertujuan untuk menaikkan tekanan agar working fluids dapat menggerakkan turbin kembali. Working fluids yang sudah dipanaskan di recuperator akan dialirkan kembali ke preheater. Sistem Brine ORC berupa closed loop, dimana working fludis tidak berkontak langsung dengan udara luar, proses closed loop berlangsung terus-menerus, Hal ini meyebabkan 
tidak dibutuhkannya penambahan working fluids terusmenerus, melainkan penambahan hanya dilakukan untuk make up dari proses.

\section{G. Proses Injeksi Ulang Fluida}

Kondensat yang berasal dari Bottoming ORC dan Brine ORC akan dicampurkan dan kemudian diinjeksikan ulang ke reservoir dengan melalui injection well.

\section{HASIL ANALISA EKONOMI}

Analisa ekonomi merupakan salah satu parameter apakah suatu pabrik tersebut layak didirikan atau tidak. Untuk menentukan kelayakan suatu pabrik secara ekonomi, diperlukan perhitungan bahan baku yang dibutuhkan dan produk yang dihasilkan.

Untuk melakukan evaluasi atau studi kelayakan dan penilaian investasi untuk pendirian suatu pembangkit listrik maka dilakukan peninjauan terhadap faktor-faktor Laju Pengembalian Modal (Internal Rate of Return/IRR), Waktu Pengembalian Modal Minimum (Pay Out Time/POT), Titik Impas (Break Even Point/BEP). Dimana menggunakan asumsi bahwa pembangkit listrik tenaga panas bumi ini akan didirikan dan siap beroperasi pada tahun 2020, dengan pembelian peralatan pada tahun 2017 dan masa konstruksi selama 2 tahun (2018-2020).

Berikut adalah uraian mengenai Analisa ekonomi Pembangkit Listrik Tenaga Panas Bumi, Blok Sarulla

\begin{tabular}{|c|c|c|c|}
\hline No. & Variabel & Unit & Jumlah \\
\hline 1 & $\begin{array}{l}\text { Total Invesment } \\
\text { Cost ( CAPEX) }\end{array}$ & US\$ & $325,219,457.18$ \\
\hline 2 & Loan VS Equity & $\%$ & 80 \\
\hline 3 & Interest & $\%$ & 11 \\
\hline 4 & Credit Investment & US\$ & $292,145,939.26$ \\
\hline 5 & Equity & US\$ & $69,222,352.97$ \\
\hline 6 & IDC & US\$ & $255,852,813.09$ \\
\hline 7 & Working Capital & US\$ & $48,782,918.58$ \\
\hline 8 & $\begin{array}{l}\text { NPV @ } 30 \text { year @ } \\
\text { I=10\% }\end{array}$ & US\$ & $18,637,856.60$ \\
\hline 9 & IRR & $\%$ & 13.2 \\
\hline 10 & POT & year & 6.9 \\
\hline 11 & Gross Revenue & US\$/yr & $197,407,584.00$ \\
\hline 12 & $\begin{array}{l}\text { Cost for Make Up } \\
\text { Working Fluid }\end{array}$ & $\mathrm{US} \$ / \mathrm{yr}$ & $172,800.00$ \\
\hline 13 & $\begin{array}{l}\text { Operation and } \\
\text { Maintenance }\end{array}$ & US\$/yr & $3,675,665.27$ \\
\hline 14 & $\begin{array}{l}\text { EBITDA ( Earning } \\
\text { Before Tax, } \\
\text { Interest, } \\
\text { Depreciation } \\
\text { Amortization ) }\end{array}$ & US\$/yr & $129,441,841.96$ \\
\hline 15 & Taxes ( $30 \%$ ) & US\$/yr & $38,832,552.59$ \\
\hline 16 & $\begin{array}{l}\text { EAIDT ( Earning } \\
\text { After Interest, } \\
\text { Depreciation, and } \\
\text { Tax ) }\end{array}$ & US\$/yr & $62,748,066.20$ \\
\hline 17 & $\begin{array}{l}\text { EAT + D ( Earning } \\
\text { After Tax and } \\
\text { Depreciation ) }\end{array}$ & US\$/yr & $98,902,385.53$ \\
\hline 18 & Project Life & years & 30 \\
\hline 19 & Construction Period & months & 24 \\
\hline 20 & $\begin{array}{l}\text { Operation } \\
\text { Days/Year }\end{array}$ & day/yr & 330 \\
\hline
\end{tabular}

\section{KESIMPULAN}

Dari hasil analisa ekonomi pembangkit listrik tenaga geothermal didapatkan IRR $13.2 \%$ yang mengindikasikan bahwa pabrik layak untuk didirikan dan waktu pengembalian modal (pay out period) selama 6.9 tahun. Perhitungan analisa ekonomi didasarkan pada discounted cash flow. Dengan modal untuk pendirian pabrik menggunakan rasio $80 \%$ modal sendiri dan $20 \%$ modal pinjaman. Sedangkan Break Event Point (BEP) yang diperoleh adalah sebesar $30.82 \%$.

\section{DAFTAR PUSTAKA}

[1] Dipippo, R. 1995. "Geothermal Energy as Source of Electricity and Case Studies", Mc Graw-Hill Inc. New York

[2] Kagel.2007. "A Guide to Geothermal Energy And The Environment “. Geothermal Energy Association, Pennsylvania

[3] Amnon Gabby. 2015. "Sarulla 330 MW Geothermal Project Key Success Factors in Development “. Proceesing World Geothermal Congress 2015, Australia

[4] Valdimarson. 2011. "Geothermal Power Plant Cycles and Main Components “. University of Iceland, Reykjavik 